de wettelijke regeling in België voor ons land opent, in een der volgende nummers aan een beschouwing te doen onderwerpen. Inmiddels achten wij het nodig, dat de lezer kennis neemt van de inhoud van het wetsontwerp en van de daarbij behorende Memorie van Toelichting. Wij plaatsen het eerste in dit nummer en de Memorie van Toelichting in het volgende.

\title{
DE BIJZONDERE FINANCIERINGSREGELINGEN EN DE FINAN- CIERING VAN HET HERSTEL
}

door Des L. F. Ras

Doel van deze beschouwing is enige aandacht te wijden aan de bijzondere financiering, haar ontstaansgrond, doel en werking, aangezien mij gebleken is, dat hiermede in een bestaande behoefte aan nadere toelichting zal kunnen worden voorzien. Ik heb niet getracht dit zeer gecompliceerde vraagstuk volledig te behandelen; de sociaal economische aspecten ervan zijn geheel onbehandeld gelaten.

Wat verstaat men onder een bijzondere financieringsregeling?

Een korte omschrijving daarvan werd gegeven in het jaarverslag van de Maatschappij tot Financiering van het Nationaal Herstel N.V. over het boekjaar 1 November 1945-31 December 1946. (Zie thans ook Ontwerp Wet Materiële Oorlogsschaden Hfst. VI, art. 70-75). Op Blz. 10 - 6e alinea lezen wij:

„Ingeval van toepassing van de bijzondere financiering stelt de Staat ,zich jegens onze instelling garant voor een gedeelte van de verplichtin..gen, welke de desbetreffende onderneming moet aangaan, om het ver ,,schil in de kosten van herstel aan de ene kant en de rijksbijdrage en ,,molestpenningen aan de andere kant te overbruggen. De Staat neemt ",deze garantie echter slechts op zich ten behoeve van die ondernemingen. ,,waarvan het herstel wordt geacht in het belang van 's lands welvaart te ,zijn en indien de ten behoeve hiervan aan te gane verplichtingen de ,rendabiliteit van de desbetreffende onderneming ernstig bedreigen ,en(of) haar mededingingskracht tegenover niet getroffen bedrijfsgeno ,ten zeer aanmerkelijk verzwakken. Op het door de Staat gegarandeerde "deel van het crediet wordt de onderneming voor rente en aflossing slechts ,belast, indien en voorzover de exploitatie-resultaten zulks toestaan. Voor „1 Januari 1956 zal over handhaving, matiging of kwijtschelding van de ,hoofdsom van de onder Staatsgarantie toegestane bijzondere financie",ringen volgens algemene regelen nader worden beslist".

Uit deze omschrijving blijkt, dat bijzondere financieringen worden toegepast bij de financiering van het herstel, voor zover dit herstel niet uit de rijksbijdrage in de oorlogsschade en/of de molestuitkeringen kan worden bekostigd, waarbij stilzwijgend is aangenomen, dat de eigen beschikbare middelen, daarvoor onvoldoende zijn. Het begrip herstel moet hierbij ruim worden opgevat in de zin van herstel van de welvaart, hetgeen betekent, dat de bijzondere financiering ook voor nieuw op te richten ondernemingen van belang voor 's lands welvaart kan worden toegepast. (Zie No. 9 1) blz. 11).

De vraag is dus: wanneer kan de rendabiliteit van een onderneming door de financiering worden bedreigd?

$\mathrm{Bij}$ de financiering is het economisch probleen voor de ondernemer:

1) De nummers verwijzen naar de lijst van publicatiën. 
a. hoe krijg ik het nodige kapitaal op de goedkoopste wijze?

b. kunnen de kosten van de verkrijging bestreden worden uit de opbrengst van het product?

In het algemeen zal bij juiste financiering de rendabiliteit niet door de financiering bedreigd worden. Indien de kosten niet uit de opbrengst van het product worden bestreden, dan is de productie klaarblijkelijk irrationeel. In dit geval zou er geen sprake zijn van een bijzondere financiering, maar van een ondersteuning op grond van andere overwegingen via een regeling gekoppeld aan de financiering.

Ik meen echter, dat men dit geval niet voor ogen had. In genoemd jaarverslag vinden wij op blz. 11 hiervoor een verdere aanwijzing.

,Het is evenwel duidelijk, dat de bijzondere financiering een niet geheel ,,bevredigende oplossing van het gesignaleerde euvel kan bieden en dat in ,het algemeen slechts verbreding van de kapitaalsbasis van de crediet"zoekende onderneming op de duur volledig uitkomst kan brengen".

En verder:

.Het is daarom ons ernstig streven naar middelen te zoeken, waardoor ,in de behoefte aan kapitaal ook in andere vorm dan in die van een lang "lopend crediet kan worden voorzien".

(Inmiddels is, volgens de Memorie van Antwoord op de Rijksbegroting 1948, op initiatief van de Herstelbank een financieringsmaatschappij in oprichting, welke uitsluitend zal financieren door kapitaaldeelneming.)

Indien ik de aanduiding in het jaarverslag van de Herstelbank goed begrijp, dan moet dus de bedreiging van de rendabiliteit en de verzwakking van de mededingingskracht nu worden gezocht in de wijze waarop de financiering plaats vindt, en waarbij blijkbaar het over te dragen vermogen van een andere soort is dan waaraan bij de onderneming behoefte bestaat. Er wordt namelijk op gewezen, dat slechts een verbreding van de kapitaalsbasis - (volgens de terminologie waarmede de lezers van dit maandblad vertrouwd zijn, dus een vergroting van het permanent vermogen) - op de duur volledige uitkomst kan brengen, in tegenstelling tot een voorziening in de vermogensbehoefte door langlopend crediet (volgens onze terminologie langdurig tijdelijk vermogen).

Wanneer er inderdaad sprake is van een behoefte aan permanent vermogen, - hierop kom ik in het vervolg van deze beschouwing nog terug - dan is het stellig irrationeel in deze behoefte met langdurig tijdelijk vermogen te willen voorzien.

Moeilijkheden ontstaan in dit geval doordat het inkomen van een groot aantal bedrijven ( $4-$ blz. il gedrukte rede) onvoldoende stabiliteit vertoont om daaruit aan de vaste verplichtingen te kunnen voldoen.

De moeilijkheden ontstaan dan door onjuiste voorziening in de vermogensbehoefte. De bijzondere financiering, welke hieraan tegemoet wil komen, ware juister aan te duiden met ondersteuningsregeling ingevolge irrationele financiering. Ik meen, dat het niet de bedoeling is geweest de z.g.n. bijzondere financiering voor deze gevallen aan te wenden.

Wederom treffen wij hiervoor in genoemd jaarverslag een aanwijzing aan, n.1. op blz. 10 - 4e alinea:

,De ervaring heeft ons reeds korte tijd nadat wij onze werkzaamheden ,waren begonnen, aanleiding gegeven ons te wenden tot de Minister van „Financiën, teneinde te onderzoeken, of er in gevallen, waarin door de ,toegebrachte oorlogsschade de rendabiliteit van het bedrijf in wezen is ,,aangetast, een extra tegemoetkoming door het Rijk ten behoeve van het "getroffen bedrijf kan worden verwacht". 
Wat is dan de gedachte welke aan de bijzondere financiering ten grondslag ligt?

Indien een bedrijf door het oorlogsgeweld is weggevaagd, dan is er ook van rendabiliteit geen sprake meer. Bij de toelichting in het jaarverslag van de Herstelbank heeft men dus het geval voor ogen gehad, dat door het herstel de rendabiliteit wordt bedreigd, d.w.z. een ongunstige verhouding ontstaat tussen het inkomen van het bedrijf en het eigen vermogen.

Aannemende dat hierbij geen sprake is van irrationele verhoudingen in de zin van (zoals hierboven reeds besproken) irrationele productie en/of irrationele financiering, wat kan dan hiervan de oorzaak zijn?

Voor de beantwoording van deze vraag is het nuttig gedeeltelijk de rede te volgen van $A$. Th. de Lange uitgesproken bij de aanvaarding van het ambt van Lector aan de Universiteit van Amsterdam op 12 Februari 1947 (zie 4). In deze rede werd, na de vele literatuur over de financiering van het herstel welke haar andacht vooral richtte op het probleem van de vermogensvorming en de vermogensoverdracht, een zeer scherpe analyse gegeven van de aard van de allerwege te constateren vermogensbehoefte.

De analyse werd beperkt tot de twee factoren, welke in de tegenwoordige omstandigheden daarvoor in het bijzonder van belang zijn n.l.:

a. de verandering van het prijsniveau

b. het tijdstip van de vervanging van de productiemiddelen, waarbij de invloed daarvan op de vermogensbehoefte wordt nagegaan.

De analyse toont aan, dat de thans bestaande vermogensbehoefte voornamelijk betrekking heeft op permanent vermogen en dat de oorzaak hiervan is de prijsstijging op de inkoopmarkten in het tijdvak van de oorlogsperiode, waarin de vervanging der bij de ruil prijs gegeven productiemiddelen niet of niet voldoende kon plaatsvinden, waardoor zelfs de bedrijven welke waarderen tegen vervangingsprijs, geen gelegenheid hadden de nodige aanvulling van permanent vermogen tot stand te brengen. $\mathrm{Nu}$ de aanvulling wederom mogelijk is, doch tegen een veel hoger prijsniveau, hebben deze bedrijven behoefte aan nieuw permanent vermogen.

De vermogenspositie van de bedrijven, welke waardeerden tegen uitgaafprijs is om begrijpelijke redenen slechter en de behoefte aan nieuw permanent vermogen groter. De vermogenspositie van bedrijven, welke door het oorlogsgeweld zijn getroffen, is het slechtst, omdat deze bedrijven niet alleen niet konden vervangen, maar bovendien voor een veel groter deel der vlottende en duurzame productiemiddelen vorderingen kregen op het Rijk en op de Molestmaatschappijen, welke immuun zijn voor de daarna opgetreden prijsstijgingen.

Maar nogmaals, indien rationeel wordt gefinancierd, dan is er geen reden om aan te nemen, dat een rationele productie door genoemde oorzaken onrendabel zou worden.

Het is wellicht het eenvoudigst daarvoor een voorbeeld ter hand te nemen.

Stelle, dat van een bedrijf de werktuigen en het fabrieksgebouw geheel werden verwoest, en dat men een investering voor herstel van de (directe) oorlogsschade overweegt. De vraag is dan - "bouwen en aanschaffen" - óf - "niet bouwen en niet aanschaffen". (Zoals in de aanvang reeds werd opgemerkt, doet deze vraag zich ook voor bij investeringen in geheel nieuwe bedrijven, - Feitelijk bij alle investeringen.)

Men geeft er zich vervolgens rekenschap van, dat ,bouwen en aanschaffen" nu betekent ",bouwen en aanschaffen tegen zeer hoge prijzen".

$E_{r}$ zijn drie mogelijkheden voor het prijsverloop: 
a. verdere stijging,

b. gelijkblijvend,

c. daling.

Het is niet de bedoeling in deze beschouwing na te gaan, welke der drie mogelijkheden waarschijnlijk tot werkelijkheid zal worden.

In het vervolg wordt uitsluitend de invloed van een prijsdaling nagegaan. Men leide hieruit niet af, dat ik die verwacht, ik spreek daarover geen mening uit.

Ad b. veroorzaakt geen bijzondere aspecten.

Ad a. is oorzaak, dat men maar zo snel mogelijk gaat bouwen en aanschaffen.

Ad c. stimuleert niet het initiatief om dadelijk tot bouwen en aanschaffen over te gaan, aangezien dan in de toekomst zal blijken, dat de investering op een ongunstig moment is geschied en daardoor op het vermogen wordt ingeteerd.

Wenst nu de Regering in 's lands belang een spoedig herstel van de productiecapaciteit, dan dient de remmende werking van een geanticipeerde prijsdaling te worden weggenomen, in het bijzonder indien de Regering zelve naar prijsverlaging blijft streven.

Naar mijn mening is het de bedoeling geweest van de bijzondere financieringsregeling, deze remmende werking weg te nemen. Met andere woorden, het gaat hierbij niet om een financiering, die is slechts middel. doch het doel is het herstel te bespoedigen, de remmende invloeden te neutraliseren.

Zo eenvoudig als $i k$ het hier gesteld heb is evenwel het bedoelde complex van verschijnselen niet. Gaan wij hierop even wat dieper in.

Het gaat dus om de invloed van een prijsstijging gevolgd door een prijsdaling, op de financiering van het bedrijf. Bezien wij daartoe eerst de prijsstijging. Het samenvallen van ruil en vervanging aannemende. voorziet de toepassing van de vervangingsprijs automatisch in de vermogensvoorziening voor financiering van de door de prijsstijging gestegen kapitaalsgrootte. Althans voorzover dit kapitaal deel uitmaakt van de economische voorraden, d.w.z. de voorraden waarvoor het prijsrisico op het bedrijf rust. (Is een bedrijf genoodzaakt bij het hoogste punt van het prijsniveau tot vervanging over te gaan, dan is het nodige vermogen aanwezig.) 2)

Daarna volgt de prijsdaling. Het bedrijf ondervindt hiervan geen gevolgen want de door de voorafgaande prijsstijging veroorzaakte groei van het stamvermogen (aangegeven door het fonds wegens prijsstijging) wordt in de volgende prijsdaling ingeteerd, het oorspronkelijke vermogen is ongehavend en verlies is niet ontstaan.

De vrije mogelijkheid voor het bedrijf tot toepassing van de vervangingsprijs was tijdens de oorlogsperiode en is ook thans nog voor werktuigen en gebouwen niet toegestaan. De vrije mogelijkheid tot vervanging bestond toen niet en bestaat nu evenmin. Ten gevolge hiervan is de auto matische voorziening in vermogen, voor financiering van de door de prijsstijging gestegen kapitaalsgrootte, gedwongen buiten werking geraakt Een fonds wegens prijsstijging ontstond niet of niet in voldoende mate Ontvangt een getroffen bedrijf de nodige vergunningen dan kan nu tot herstel (vervanging) worden overgegaan. Die vervanging geschiedt dan. zich rekenschap gevende van een te verwachten prijsdaling, op het duurste moment op de top van de golf in het prijsverloop.

${ }^{2}$ ) Zie 4 - verondersteld is, dat de kapitaalcomponenten bij voortduring een gelijke grootte vertonen.

$\mathrm{m} \mathrm{a} \mathrm{b}$ blz. 106 
Men rekent in de toekomst op het vermogen in te teren. Zoals reeds gezegd is er geen of geen voldoende fonds wegens prijsstijging, waarmede deze intering op het vermogen kan worden gecompenseerd en indien het vermogen niet uit het inkomen kan worden aangevuld zal het worden aangetast. Hierdoor wordt de rendabiliteit bedreigd.

In alle bedrijven, met of zonder directe oorlogsschade, zal een geanticipeerde prijsdaling een remmende invloed op de vervanging (het herstel) uitoefenen. In de practijk is het veelal mogelijk de vervanging technisch te verschuiven.

Bedrijven door directe oorlogsschade getroffen, kunnen echter de vervanging niet uitstellen, aangezien het alternatief dan is, werkloos afwachten.

Nog meerdere invloeden kunnen optreden, welke de waarneembare verschijnselen meer of minder zullen wijzigen.

Zodra tot vervanging wordt overgegaan wordt de vervangingsprijs uitgaafprijs. In het geval het getroffen bedrijf deel uitmaakt van een bedrijfsgroep met vrijwel uniform product, leidt dit tot complicaties. (zie ook 8). Volgens de officiële richtlijnen zou het getroffen bedrijf een prijs voor zijn product mogen berekenen, welke hoger is dan de prijzen. welke de overige bedrijven uit de bedrijfsgroep voor gelijke producten mogen rekenen. Gewoonlijk echter gelden voor uniforme producten min of meer uniforme prijsregelingen.

Worden deze regelingen gebaseerd op de uitgaafkosten der niet getroffen bedrijven dan komt het getroffen bedrijf in het nadeel en dan is als het ware bij de investering dus reeds vermogen teloor gegaan en wordt daardoor de rendabiliteit bedreigd.

Typisch wordt het voorgaande gedemonstreerd bij de woningbouw. Sielselmatig zijn de huren gehandhaafd op een peil, waarbij het verband met de bouwkosten, welke een enorme stijging te zien geven, is verbroken. De rendabiliteit van het in woningbouw te investeren vermogen is tengevolge hiervan allerminst verzekerd. Integendeel, reeds dadelijk gaat daarvan een deel teloor.

Teneinde de remmende werking hiervan op het herstel weg te nemen is de renteloze hypotheekregeling uitgevaardigd. (zie Financieringsregeling Woningbouw 1947 Ned. Stcrt. 27 Jan. '47 No. 18) Ten aanzien van de hoofdsom zal tijdens of na 10 tot 15 jaar over, gehele of gedeeltelijke kwijtschelding een beslissing worden genomen.

Voor getroffen bedrijven in de industrie kunnen, door onvermijdelijk herstel, op de top van de golf in het prijsverloop, overeenkomstige omstandigheden voortvloeien. Daarbij kan een ongunstige rendabiliteit worden veroorzaakt door een verbroken verband tussen het prijsniveau van de vaste activa en het prijsniveau voor het gereed product of wel een toekomstige daling van het prijsniveau van de vaste activa.

Zoals reeds betoogd, wil een regeling, gekoppeld aan de financiering en aangeduid met de bijzondere financieringsregeling, de remmende werking opheffen van een geanticipeerde prijsdaling op het herstel en daartoe het eventuele verlies door intering van het vermogen wegnemen. De financiering is hierbij slechts middel.

Hieruit blijkt ook, dat de bijzondere financiering niet kan zijn een verbreding van de kapitaalsbasis (permanent vermogen). Is de bijzondere financiering hiervoor nodig, dan is blijkbaar sprake van een irrationele financiering.

Ook andere middelen waren denkbaar om de remmende werking van een geanticipeerde prijsdaling op te heffen, n.l. 
1e. gekoppeld aan een fiscale regeling,

2e. gekoppeld aan een prijsregeling.

Ad 1. Een fiscale regeling in bedoeld opzicht treffen wij aan in de Resolutie d.d. 7 November 1946 No. 1, (I.B.) waarbij voor nieuwe investeringen een versnelde afschrijving in de eerste jaren (door afschrijving van een vast percentage op de boekwaarde) wordt toegestaan.

Hierdoor wordt het mogelijk, voor zover de opbrengsten het toelaten, alsnog een situatie te scheppen overeenkomende met die, waarbij een meer of minder groot fonds wegens prijsstijging aanwezig zou zijn.

Ad 2. Een individuele prijsregeling kan aan getroffen bedrijven toestaan, de hoge uitgaafprijs voor nieuwe investeringen volledig in de prijs aan consumenten door te berekenen.

De terugkeer van de concurrentie kan deze mogelijkheid doen vervallen.

De bijzondere financieringsregeling kan men (zie $9-$ blz. 10) zich als volgt voorstellen, tenminste tot 1 Januari 1956.

Stelle b.v.:

a. Verleend crediet $f$ 400.000. - waarvan $f$ 200.000. - bij wijze van bijzondere financiering. Looptijd 10 jaar. Rente $5 \%$. Aflossing $f$ 40.000. - per jaar.

b. Totale investering $f$ 600.000. - ingebouwen en werktuigen. Afschrijving gemiddeld $7 \%$ per jaar.

c. Getaxeerd is, dat voor $1 / 3$ te duur wordt gebouwd.

Resultaat voor het jaar 19... (1e jaar, op de top van de golf in het prijsverloop), opbrengst product $/$. kosten (zonder

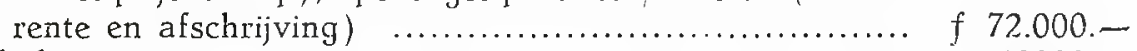

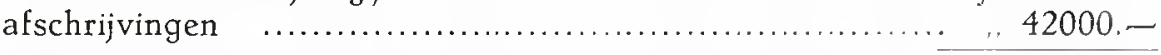

restant ............................................... f $30.000 \ldots$

rente gewoon crediet a $5 \%$

restant ................................................ f 20.000 -

Verplichtingen:

af te lossen $f$ 40.000. - ; te betalen rente $f$ 20.000.- .

Resultaat voor het jaar $19 \ldots$ (2e jaar prijsdaling gebouwen

en werktuigen $1 / 6$ ), opbrengst product $\%$ kosten (zon

der rente en afschrijvingen) (....................... f 50.000.

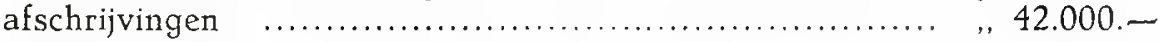

restant ..................................................... f 8.000.-

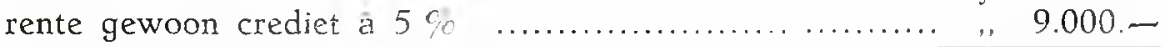
tekort

f $1.000 .-$

Verplichtingen:

af te lossen $f$ 40.000. - , te betalen rente $f$ 18000. - waarvan $f$ 8.000. - wordt kwijtgescholden, want $(50.000-40.000-9.000)$ is 8.000 kleiner dan 9.000 rente b.f. (zie thans ook Ontwerp Wet op de Materiële Oorlogsschaden, art. 7i (6).

Want, zoals uit het eerste citaat blijkt: ,wordt de onderneming voor rente en aflossing belast, indien en voor„zover de exploitatie-resultaten zulks toelaten".

Hieruit volgt,dat blijkbaar de gedachte heeft voorgezeten, althans voorlopig de onderneming naar draagkracht d.w.z. op grond van haar rendabiliteit te doen meedragen in de verliezen, die bij prijsdaling zullen voortvloeien uit een investering op een ongunstig moment, n.l. bij hoge prijzen. 
Eerst indien in het $2 e$ jaar een zesde deel van de investering of f 100.000. - op de bijzondere financiering wordt kwijtgescholden, ontheft die kwijtschelding het bedrijf van het nadeel, voortvloeiende uit de te dure investering, t.o.v. niet getroffen bedrijven.

Het streven, althans voorlopig de rendabiliteit van het bedrijf in bedoeld nadeel te doen meedragen, heeft o.m. als bezwaar, dat de goede bedrijven, n.l. die welke zich de grootste voorsprongspremiën hebben weten te verschaffen, het zwaarste mededragen in de nadelen. Bovendien zal door deze voorlopige regeling worden opgevangen een te grote last, die op het bedrijf wordt gelegd door irrationele financiering, d.w.z. een omvangrijke financiering met langdurig tijdelijk vermogen.

De zogenaamde ondergekapitaliseerde bedrijven vormen voor de aangegeven regeling een belangrijk struikelblok.

Met ondergekapitaliseerde bedrijven zou ik willen aanduiden die bedrijven, waarbij het in de balans vermelde vermogen, voorzover dit vermogen moet voorzien in de financiering van kapitaal, deel uitmakende van de economische voorraden, niet meer aangeeft de feitelijke vermogensgrootte nodig voor de continuering van het bedrijf, maar een kleinere vermogensgrootte. In het bijzonder kan dit bij gereorganiseerde bedrijven het geval zijn.

In het algemeen heeft evenwel bij prijsstijging de toepassing van waardering tegen uitgaafprijs - hetzelfde gevolg.

Dit kan dan een schijnrendabiliteit tot gevolg hebben gehad, welke nu bij vervanging, bij handhaving van de continuiteit, natuurlijk wordt aangetast. In dit geval zou het gevolg van de bijzondere financieringsregeling kunnen $z \mathbf{i j n}$, dat een in feite onrendabel bedrijf in leven wordt gehouden.

Ik hoop met deze beschouwingen aan de lezer een indruk te hebben gegeven van de gedachte, welke blijkbaar aan de bijzondere financieringsregeling ten grondslag heeft gelegen, alsmede van de talrijke factoren, welke hierbij hun invloed kunnen doen gelden.

Voor belangstellenden laat ik hierbij een lijst van publicatiën welke op het behandelde onderwerp betrekking hebben volgen.

1. Prof. Dr. Th. Limperg Jr., De gevolgen van de depreciatie van de gulden voor de bepaling van waarde en winst. M.A.B. 1937.

2. Dt. P. P. van Berkum, Financiering der onderneming in na-oorlogstijd. Economie 10e jaarg. Afl. 10/11, 1946.

3. Drs. J. F. Posthuma, De economische betekenis van de Maatschappij tot Financiering van het Nationaal Herstel N.V. Haar organisatie en haar wijze van werken. De Economist, 95e jaarg. Afl. 1, 1947.

4. A. Th. de Lange, De invloed van prijsstijging en uitgestelde vervanging der productiemiddelen op de financiering van het bedrijf. Rede uitgesproken bij de aanvaarding van het ambt van Lector aan de Universiteit van Amsterdam, op 12 Februari 1947.

5. C. A. Klaasse, Wisselkoers, prijspeil, heffingen en de financiering van ons bedrijfsleven. Econ. Stat. Berichten, 6 Maart '46, blz. 149 e.v.

6. Dr. J. F. Haccoû. De financiering door de Herstelbank. Maandblad voor Accountancy en Bedrijfshuishoudkunde, blz. 150, e.v. 21e jaarg. No. 5, 1947.

7. Drs. C. Aerts, De Regeling der oorlogsschade en de vervangingswaarde. Economie. 10e jaarg. af1. 4/5, 1946, blz. 161, e.v.

8. Dr. Th. H. Mulders, Het vraagstuk der aanvullende financicring. Economie, 10e jaarg. afl. 10/11, 1946. Blz. 337 e.v.

9. Verslag van de Maatschappij tot Financiering van het Nationaal Herstel N.V. over het boekjaar 1 Nov. 1945-31 Dec. 19.46. 